\title{
Did Terrorism Affect Voting in the Brexit Referendum?
}

\author{
Vincenzo Bove ${ }^{1 *}$ (D), Georgios Efthyvoulou ${ }^{2}$ and Harry Pickard ${ }^{2}$ \\ ${ }^{1}$ Department of Politics and International Studies and CAGE (Competitive Advantage in the Global Economy), University of \\ Warwick, Coventry, UK and ${ }^{2}$ Department of Economics, University of Sheffield, Sheffield, UK \\ ${ }^{\star}$ Corresponding author. E-mail: v.bove@warwick.ac.uk
}

(Received 14 January 2020; revised 2 July 2020; accepted 28 December 2020; first published online 21 April 2021)

\begin{abstract}
This article contributes to the recent research on Brexit and public opinion formation by contending that the determinants of the referendum results should be evaluated against the background of wider public security concerns. The British public has long regarded terrorism as a top concern, more so than in any other European country. Terrorist attacks on UK soil raised voters' awareness of security issues and their saliency in the context of the EU referendum. The study finds that locations affected by terrorist violence in their proximity exhibit an increase in the share of pro-Remain votes, particularly those that experienced more sensational attacks. Using individual-level data, the results show that in the aftermath of terrorist attacks, citizens are more likely to reconsider the security risks involved in leaving the EU.
\end{abstract}

Keywords: Brexit; security; terrorism; voting; referendum

On 23 June 2016, the United Kingdom (UK) voted to leave the European Union (EU) by a margin of 3.78 per cent - 51.89 per cent for Leave and 48.11 per cent for Remain. The unexpected outcome caught many scholars, pollsters and practitioners by surprise and spurred a growing academic literature on the determinants of the Brexit vote. Socio-economic characteristics enjoy near-consensus support, and the pro-Leave vote is often explained by financial dissatisfaction, the prevalence of national identity, including previous support for UKIP, and social status (see, for example, Becker, Fetzer and Novy 2017; Chan et al. 2017; Clarke, Goodwin and Whiteley 2017b). Older and less educated individuals were also more likely to be pro-Brexit (Chan et al. 2017; Goodwin and Heath 2016). Furthermore, economic distress in 'left-behind' areas of globalization and austerity-induced welfare reforms played an important role in support for the Leave option (Colantone and Stanig 2018; Fetzer 2019).

Our article contributes to recent research on Brexit and public opinion formation by contending that the determinants of the referendum results should also be evaluated against the background of wider public security concerns. The UK has a long history of battling episodes of terrorism and political violence within its borders. In 2015 and 2016 alone, twenty-nine terrorist incidents were recorded in the country, excluding Northern Ireland. And in 2017, the year after the Brexit vote, emblematic terrorist attacks, such as those at Westminster Bridge, Manchester Arena and London Bridge, killed a total of thirty-six people. Not surprisingly, a 2015 YouGov poll of the public's global concerns shows that UK citizens regard international terrorism as the biggest threat, whereas in other European countries economic uncertainty usually tops the list. ${ }^{1}$

\footnotetext{
${ }^{1}$ Available online: https://tinyurl.com/y96pb48x.

(c) The Author(s) 2021. Published by Cambridge University Press. This is an Open Access article, distributed under the terms of the Creative Commons Attribution-NonCommercial-NoDerivatives licence (https://creativecommons.org/licenses/by-nc-nd/4.0/), which permits noncommercial re-use, distribution, and reproduction in any medium, provided the original work is unaltered and is properly cited. The written permission of Cambridge University Press must be obtained for commercial re-use or in order to create a derivative work.
} 
Extant studies have thus far neglected whether and how security concerns have shaped support for Brexit. Since 9/11, the social and political implications of terrorism have been active areas of academic debate. Terrorist attacks often receive prominent media coverage and public attention, and can affect public attitudes and policy outputs (Legewie 2013; Neumayer, Plümper and Epifanio 2014). We claim that terrorist attacks on UK soil raised voters' awareness of security issues and their saliency in the context of an EU referendum. Other studies show that terrorism increases voter turnout and right-wing votes (Balcells and Torrats-Espinosa 2018; Berrebi and Klor 2008; Getmansky and Zeitzoff 2014). We depart from these studies by demonstrating that terrorism not only affects party preferences, but also public support for broader political and economic issues, such as European integration. At the same time, studies on EU-related referendums show status quo bias because voters are concerned about drastic economic consequences (Atikcan 2015), but ignore changes in preferences when voters are cued on potentially drastic public security consequences.

We offer a rigorous empirical analysis that can inform public debates on the impact of security concerns on Brexit and shed light on how political attitudes are formed. The main identifying variation in our analysis is the distance from a terrorist event. For the average terrorist incident, we assume that the effect is a function, inter alia, of geographic proximity - an individual's physical distance from the place where the event occurred. Geographic proximity heightens the perception of threat and affects the extent to which an event is covered by the local media (Böhmelt, Bove and Nussio 2019). Physical proximity to attacks amplifies the personal sense of vulnerability (Braithwaite 2013), as well as the perception of risk in terms of both the probability and the consequences of terrorist events (Fischhoff et al. 2003). Physical proximity has also been shown to increase counterfactual thoughts - individuals thinking that 'they themselves could have suffered from a disaster if the circumstances had been a bit different' (Zagefka 2018, 5).

We put forward two competing hypotheses on the impact of terrorism on support for Remain. On the one hand, several studies indicate more support for reactionary nationalist, right-wing and anti-immigration parties after a terrorist attack (Berrebi and Klor 2008; Davis and Deole 2017; Legewie 2013). As terrorism can affect anti-foreigner sentiments and increase concerns about less restrictive immigration policies, we expect weaker support for Remain in locations near terrorist attacks. On the other hand, terrorist attacks may expose national security vulnerabilities and increase awareness of the additional security risks of leaving the EU or make citizens more open to EU-wide solutions (Larsen, Cutts and Goodwin 2019). In a context in which terrorism targets other EU countries and the media explicitly link terrorism to the risks of Brexit, we can expect voters to react to terrorism by seeking to maintain the status quo. Hence, our second competing hypothesis predicts that support for Remain is stronger as distance from terrorist attacks decreases.

We proceed in two steps. First, we exploit data on 380 local authority districts and analyse the spillover effects of terrorism on the Remain vote. To do so, we employ a closest terrorist-hit district fixed effects strategy, where we use differences in distances from the same neighbouring attacked district as the identifying source of variation in terrorism exposure. We find support for the hypothesis that terrorism increases the share of votes in favour of the EU. In our most conservative estimate, we show that two non-attacked districts - within the same attack cluster - that differ by $45 \mathrm{kms}$ in their proximity to the attacked district are expected to differ by 1 percentage point in terms of support for Remain. We also show that the distance-induced Remain effects persist when we instrument contemporary distance with historical distance from terrorism, when we study within-attackeddistrict variation using data at the electoral ward level, and when we perform a series of robustness checks. Finally, we explore the conditionality of the effects on the context surrounding the attacks, throwing light on possible mediating factors. We find that proximity to terrorism has a much stronger effect on the Remain vote when the attacks attracted prominent national media coverage, when they caused casualties, and when they involved Muslim or jihadist perpetrators.

In the second step, we use individual-level data from the British Election Study (BES). This data allows us to provide further insights into the mechanisms behind our district-level results 
and to substantiate our causal claims. To this end, we employ a quasi-experimental design that exploits the occurrence of an unexpected event (terrorism) during the fieldwork of a survey to assign respondents into treatment and control groups as good as randomly (Balcells and Torrats-Espinosa 2018). We find that, in the wake of terrorist attacks, individuals are more likely to report positive attitudes about the EU and to perceive higher risks of terrorism if the UK leaves the EU. In line with our district-level results, we also find that these effects are much stronger for individuals living in counties in which terrorist attacks took place. To lend further credibility to the causal estimates, we implement Muñoz, Falcó-Gimeno and Hernández's (2020) best practices in the form of alternative estimation strategies and robustness checks - such as controlling for the baseline level of our outcome variable, using matching techniques to ensure covariate balance and testing for unrelated time trends - and our conclusions do not change.

\section{Theory}

In recent years, a growing literature has highlighted the adverse effects of terrorist violence on political trust and attitudes as well as on individual behaviour (Birkelund et al. 2019). The main political consequences of terrorism observed across studies are related to a rallying-around-the-flag dynamic, with increased approval of presidents and trust in government, nationalist votes and turnout (Balcells and Torrats-Espinosa 2018; Dinesen and Jæger 2013; Getmansky and Zeitzoff 2014). Terrorism reinforces hardline beliefs and may trigger hostility against immigrants, even when the threat is only perceived (Huddy et al. 2005; Legewie 2013; Nussio, Bove and Steele 2019).

The link between terrorism and migration has become increasingly common in the political discourse within the EU. Despite a lack of evidence to support an objective association between migration and terrorism, strict immigration policies are often justified as a response to the threat of transnational terrorism that allegedly operates and infiltrates migration flows (Bove and Böhmelt 2016; Bove, Böhmelt and Nussio 2021). Within the EU, negative attitudes towards immigrants are also associated with higher levels of Euroscepticism because the abolition of borders and free movement of people increase feelings of exposure to security threats and terrorism (McLaren 2002). The Leave campaign's narrative of 'taking back control' included immigration issues, often framed in relation to generous fiscal transfers. There were also abundant references to the threat posed by a borderless Europe. Leave campaigners highlighted that as an EU member, the UK has lost control over national borders and is powerless against terrorist threats; mere membership in the EU, they argued, is a sign that welcomes terrorists to Europe. ${ }^{2}$

As such, terrorist attacks can increase support for Brexit through a rally-around-the-flag effect. Terrorist attacks foster nationalist and patriotic feelings by reinforcing in-group social cohesion. As a consequence, voters are expected to be more supportive of the UK allegedly regaining independence from the EU. Furthermore, feelings of fear and anxiety in the aftermath of terrorism reinforce in-group cohesion at the expense of out-groups, thus further reducing support for the EU and its communitarian policies. As a result, support for Remain decreases. The rallyaround-the-flag effect is expected to unfold the closer voters are to terrorist attacks. These arguments lead to the following hypothesis:

Hypothesis 1a: Proximity to terrorism decreases support for Remain.

From a psychological perspective, the implications of terrorism and other violent events on individuals are not always primarily negative. In their review of the topic, Vázquez, Pérez-Sales and Hervás $(2008,70)$ conclude that 'terrorist attacks - originally planned to weaken society can sometimes act as catalysts to develop strengths related to human relations, to improve social and community aspects, and even philosophical or spiritual aspects'. While terrorist attacks do positively affect national pride and intragroup cohesion, this is not necessarily accompanied by

\footnotetext{
${ }^{2}$ http://www.voteleavetakecontrol.org/briefing_safety.html.
} 
more negative world views, such as trust in other people. More importantly, a sense of community and solidarity are among the most common positive feelings reported after a terrorist attack (Vázquez, Pérez-Sales and Hervás 2008). And in a recent study, Larsen, Cutts and Goodwin (2019) find that, after the 2016 Berlin attack, people in Germany held more positive attitudes towards the EU and did not change their feelings about immigrants and refugees. One suggested mechanism is more openness to EU-wide solutions. Furthermore, the political context also influences emotional responses to terrorism. According to Huddy and Feldman (2011), anger leads to reduced risk perception, more aggressive responses and greater risk taking in order to change a situation; conversely, anxiety results in the overestimation of threats and careful, systematic information processing, and thus a general preference for the status quo.

Exposure to terrorism increases stress, fear and anxiety in the population (Huddy et al. 2005). Terrorism in Europe seems to have mostly spurred anxiety rather than anger. Rather than a vengeance rhetoric, terrorist attacks in Paris have been followed by calls to 'go about normal life' as an act of resistance against terrorism (Browning 2018). Similarly, following the attacks in London and the media depiction of a nation still 'reeling' from the Manchester Arena bombing and 'under siege', social media users in the UK were outraged by such coverage and replied by resuming the World War II slogan of 'Keep Calm and Carry On'. And research in neuropsychology suggests that anxiety and fear result in greater risk aversion and the increased use of reason, searching for information and reflective judgement (for example, Marcus, Neuman and MacKuen 2000). In the context of the Irish referendum on the 'Fiscal Compact' treaty, Garry (2014) shows that anxious and fearful citizens were more likely than angry citizens to learn about the substantive content of the treaty, reflect upon it and vote on the basis of its implications. Whereas anger affected support for the 'risky' referendum option, anxiety affected support for the option framed as 'non-risky'. 'The great struggle was between fear and anger - and fear won' (Irish Times, cited in Garry 2014). Independence referendums, such as the 2014 referendum on Scottish independence, offer particularly uncertain choices with high stakes. Liñeira and Henderson (2019) find that, when faced with uncertainty, risk-averse voters prevent losses by voting against change. As such, risk attitudes play a particularly important role in vote choice.

Early in the Brexit campaign, the Remain camp had three core arguments - that remaining would be better for the economy, security and the UK's place in the world. In fact, the Remain camp explicitly argued that the UK would be more secure inside the EU, because the EU has effective tools to fight common threats, such as terrorism and global warming. A main concern was Britain losing access to EU databases on border crossings and police stops (used to track terrorists), which increased significantly after the spate of terrorist attacks in 2015 . $^{3}$ David Cameron himself asserted that EU membership made Britain safer, hinted that Brexit might increase the risk of conflict and even said the so-called Islamic State would be pleased if the UK left the EU. ${ }^{4}$ In a similar vein, prominent policy makers, such as the former heads of GCHQ, MI5 and MI6, former CIA Director David Petraeus, the head of Europol, Defence Secretary Michael Fallon and other leading figures, suggested that leaving would present real risks to security and counter-terrorism efforts. ${ }^{5}$

And although the Remain camp's message became more focused on economic concerns as the campaign unfolded, using novel survey data Atikcan, Nadeau and Bélanger (2020) show that 43 per cent of Remain supporters cited the UK's ability - as an EU member - to fight more effectively against terrorism to justify their choice. And perhaps more importantly, the media significantly contributed to reinforcing the link between UK public security and the key role of the EU as a security provider. Since the 2004 bombings of commuter trains in Madrid, the number of

\footnotetext{
${ }^{3}$ By one estimate, British law enforcement officials consulted the Schengen Information System 539 million times in 2017. Available online at: https://tinyurl.com/y6kdedyu.

${ }^{4}$ Available online at: https://tinyurl.com/yxkzyhgp, https://tinyurl.com/yxrkcg24.

${ }^{5}$ Available online at: https://tinyurl.com/y63t3oww.
} 
jihadist terrorist attacks has increased in Europe, leading to growing concerns about the security of targeted countries. Regardless of their initial attitude towards Europe, terrorism might make voters more concerned about the issue of security and more aware that it is important to them, or make them change their opinion of Europe as a provider of security. Consistent with feelings of anxiety pushing people to reassess and carefully evaluate information, Goodwin, Hix and Pickup (2020) show that voters' familiarity with Eurosceptic arguments reduced the influence of the latter and in favour of less familiar pro-EU ones, which were more likely to shape voting decisions.

Fighting terrorism was one of the less familiar but highly prominent arguments, particularly for those living near targeted areas. Atikcan, Nadeau and Bélanger (2020) note that the case of Brexit distances itself from other EU or independence referendums in which highly risky economic consequences of change pushed people to vote in favour of the status quo. We argue that in the aftermath of terrorist attacks, citizens become more aware of the salience of security and terrorism and reconsider the security risks involved in leaving the EU. As in the case of risky economic consequences generating a pro-status quo bias, terrorism may result in a similar change in preferences towards the seemingly less risky option, to Remain. This would also explain why voters do not punish incumbents after terrorist events; they instead support them and the status quo 'as a way to confront terrorists' (Balcells and Torrats-Espinosa 2018). Consistent with this discussion, we formulate a countervailing hypothesis as follows:

Hypothesis 1b: Proximity to terrorism increases support for Remain.

Before turning to the empirical analysis, we provide information about the data and variables, and some institutional context of the Brexit vote and background material on terrorism in the UK.

\section{Region-Level Analysis: Data and Variables}

\section{Dependent Variable: Remain Votes}

Appendix Figure A.1 presents a map of support for the Remain side across local authority districts. We use the percentage of votes for Remain at the district level from the Electoral Commission, and complement this information with data at the ward level from Rosenbaum (2017).

\section{Main Explanatory Variable: Terrorism}

Data on terrorism are taken from the Global Terrorism Database (GTD). Terrorism is defined as 'the premeditated use or threat to use violence by individuals or sub-national groups against noncombatants in order to obtain a political or social objective through the intimidation of a large audience beyond that of the immediate victims' (Enders, Sandler and Gaibulloev 2011, 321). We choose a relatively wide window and consider all terrorist attacks from January 2013 to 23 June 2016. January 2013 is a representative month as David Cameron first mentioned the EU referendum on 23 January $2013 .^{6}$ After the announcement was made, the public debate increasingly focused on the costs and benefits of leaving the EU. ${ }^{7}$ There was also a sharp increase in the frequency of terrorist attacks in the UK in 2013 (see Appendix Figure A.2). Given the likely stronger impact of more recent episodes, we also run models in which we weight our coefficients by the time since the last terrorist attack.

Appendix Figure A.3 maps terrorist incidents in the UK from January 2013 to the referendum date. A total of forty-three districts were targeted by terrorist violence; not surprisingly, London experienced the most incidents. Yet the attacks were scattered around the country, and even if

\footnotetext{
${ }^{6}$ Available online at: https://www.bbc.co.uk/news/uk-politics-21148282.

${ }^{7}$ Available online at: https://tinyurl.com/yxnmogdf.
} 
terrorism per se is a rather rare event for the average district, all districts are exposed to neighbours' attacks. A string of terrorist attacks has hit the country in recent years. There were several emblematic attacks before the Brexit vote. Jo Cox, a member of parliament (MP) who campaigned against leaving the EU, was assassinated in June 2016. In December 2015, three people were stabbed in east London by an attacker driven by Islamic extremism. In February 2014, the New Irish Republican Army claimed responsibility for a series of parcel bombs sent to army recruitment offices in at least seven cities or towns in England. In May 2013, a British soldier, Lee Rigby, was murdered in an attack in Woolwich by two Islamist extremists. These attacks resulted in a corresponding record high number of terrorism-related arrests in Britain - 441 as of March 2018. ${ }^{8}$ As noted above, terrorism is becoming an increasing concern for the British public.

\section{Control Variables}

Following previous research on the determinants of the Brexit vote (Becker, Fetzer and Novy 2017; Chan et al. 2017; Clarke, Goodwin and Whiteley 2017a; Colantone and Stanig 2018; Goodwin and Milazzo 2017; Pickard 2019), we control for a broad set of variables that may confound the relationship between terrorism and the referendum returns. As in prior studies (see, for example, Becker, Fetzer and Novy 2017), we link data from the 2001 and 2011 censuses using changes and growth rates to capture changing trends.

To account for the impact of education attainment on vote choice, we control for the growth in the share of highly educated people, defined as the share of citizens with an undergraduate degree, professional qualification or equivalent. To capture the important role of immigration in predicting the referendum outcomes, we include growth rates in the local population shares of three immigration-origin groups: the fifteen 'old' EU member states, the twelve states that joined in 2004 and 2007, and non-EU countries. To address the claim that the Leave campaign resonated particularly well among voters in areas that had experienced a prolonged economic downturn (Becker, Fetzer and Novy 2017), we control for the change in the share of the population that is employed in the manufacturing sector and the change in the median hourly pay. We also add to the specification the share of value added in a UK region that can be attributed to consumption and investment demand in the rest of the EU as a proxy for 'globalization' and 'EU trade integration', and the change in the share of Muslim population to capture changing trends in the district's religious diversity.

Finally, we include a set of variables that are potentially correlated with terrorism exposure, but may also be relevant for explaining the referendum outcomes (see, for example, Marineau et al. 2020). Specifically, we control for population density, a measure of crime (the logarithm of the district's total number of crimes and offences) and a measure of attack history (a binary indicator coding districts that experienced terrorist attacks between January 1996 and December 2012). Further discussion of the choice of control variables, and a full description of all variables used in the regional-level analysis (together with the corresponding data sources), is provided in Appendix Section A.1.

\section{Region-Level Analysis: Empirical Design and Findings Methodology}

To test our hypotheses, we employ data at the local authority district (LAD) level, which comprises 380 spatial units across England, Scotland and Wales. Our estimation strategy exploits the fact that only 11 per cent of these districts were hit by terrorist attacks during the sampled period, and uses the distance of non-attacked districts from their closest attacked district as the identifying source of variation. The idea behind this method is that, by focusing on 'spillover effects' rather than direct exposure effects, we can address self-selectivity concerns (Bratti et al.

\footnotetext{
${ }^{8}$ Available online at: https://tinyurl.com/ydgn8coj.
} 
2017); that is, unobserved factors - not fully captured by our covariates - that may affect both a district's likelihood of experiencing terrorist attacks and the voting behaviour of its residents. Specifically, our empirical model takes the following form:

$$
{ }^{'} \text { Remain' }_{i}=\beta_{0}+\beta_{1}{ }^{'} \text { Distance }_{i j}+\beta_{2} X_{i}+\mu_{c}^{j}+\varepsilon_{i}
$$

where 'Remain' ${ }_{i}$ is the Remain vote share in district $i$ (ranging from 24.4 to 78.6 per cent); 'Distance' ${ }_{i j}$ is the centroid-to-centroid distance in kilometres between district $i$ and the closest terrorist-hit district $j ; X_{i}$ is a vector of district's covariates; $\mu_{c}^{j}$ represents fixed effects at the attack cluster level $c$, with each cluster consisting of all districts with the same closest terrorist-hit district $j$ (forty-three clusters in total); and $\varepsilon_{i}$ is an error term, clustered at the same level. Our parameter of interest, $\beta_{1}$, measures the effect of proximity to terrorism on the Remain vote; a positive value supports Hypothesis 1a (proximity to terrorism decreases support for Remain) and a negative value supports Hypothesis $1 \mathrm{~b}$. Under this setting, the key identification assumption is that the occurrence of a terrorist attack in district $j$ is not correlated with unobserved determinants of the Remain vote in district $i$, where $i \neq j .{ }^{9}$

$X_{i}$ includes the control variables described above. As already mentioned, these variables can serve as potential predictors of the likelihood of experiencing terrorism or have been identified as significant correlates of the Brexit referendum returns in prior studies. However, to strengthen our identification assumption, we also experiment by adding a wide range of additional observable characteristics at the district $i$ level. Furthermore, to account for residual heterogeneities related to macro-region idiosyncrasies, we augment Equation 1 with fixed effects at higher tiers of sub-national division: countries and government office regions (GORs). ${ }^{10}$ Finally, we report instrumental variable (IV) estimates of Equation 1, where 'Distance' ${ }_{i j}$ is instrumented with 'historical' distance from terrorism, and perform a series of robustness and sensitivity checks, including a within-attacked-district analysis.

\section{Main Results}

Table 1 shows our main results. ${ }^{11}$ Column 1 reports the estimates from Equation 1 based on the baseline working sample of non-attacked districts, and provides strong evidence in favour of Hypothesis 1b. In particular, we observe a negative (positive) and highly statistically significant effect of distance from (proximity to) terrorism on support for Remain: a $1 \mathrm{~km}$ decrease in distance increases the Remain vote share by 0.022 percentage points. This effect is substantively nonnegligible: two non-attacked districts - within the same attack cluster - that differ by $45 \mathrm{~km}$ in proximity to the attacked district are expected to differ by 1 percentage point in terms of support for Remain. In Columns 2-7, we augment the specification of Column 1 with additional district-level controls, which are first introduced separately and then jointly. In line with arguments presented in the relevant literature (Becker, Fetzer and Novy 2017; Chan et al. 2017; Fetzer 2019), we include the pre-referendum share of UKIP supporters (UKIP), the extent of total fiscal cuts over the period 2010-2015 (Austerity Shock), the growth rate in the share of the population aged 60 or older (Pensioner Share Growth) and the district's total population (Population).

To capture the impact of social media on political attitudes, we also include a binary indicator for districts with high Twitter usage per capita (Twitter Usage). The effect of distance remains

\footnotetext{
${ }^{9}$ One concern associated with this strategy is that a district's characteristics (which, in turn, may affect the voting behavior of its residents) may be spatially correlated. In Appendix Section B.2 we show that the probability that the neighbouring districts being attacked cannot be significantly predicted by any observable characteristics (after excluding the actual attacked districts).

${ }^{10}$ England, Scotland and Wales (countries) are divided into eleven GORs.

${ }^{11}$ In Appendix Section A.3, we report the results of the full set of variables included in vector $X_{i}$.
} 
Table 1. Terrorism and the Remain vote

\begin{tabular}{|c|c|c|c|c|c|c|c|}
\hline & 1 & 2 & 3 & 4 & 5 & 6 & 7 \\
\hline Distance & $\begin{array}{c}-0.022^{\star *} \\
(0.045)\end{array}$ & $\begin{array}{r}-0.024^{\star} \\
(0.051)\end{array}$ & $\begin{array}{c}-0.027^{\star *} \\
(0.011)\end{array}$ & $\begin{array}{c}-0.023^{\star *} \\
(0.036)\end{array}$ & $\begin{array}{c}-0.022^{\star *} \\
(0.045)\end{array}$ & $\begin{array}{c}-0.026^{\star *} \\
(0.025)\end{array}$ & $\begin{array}{c}-0.030^{\star *} \\
(0.011)\end{array}$ \\
\hline UKIP support & & $\begin{array}{c}-1.997^{\star \star \star} \\
(0.000)\end{array}$ & & & & & $\begin{array}{c}-1.485^{\star \star \star} \\
(0.000)\end{array}$ \\
\hline Austerity shock & & & $\begin{array}{c}-3.770^{* * *} \\
(0.000)\end{array}$ & & & & $\begin{array}{l}-3.627^{\star \star \star} \\
(0.000)\end{array}$ \\
\hline Pensioner share growth & & & & $\begin{array}{c}0.472 \\
(0.414)\end{array}$ & & & $\begin{array}{c}-0.642 \\
(0.311)\end{array}$ \\
\hline Population & & & & & $\begin{array}{c}0.717 \\
(0.138)\end{array}$ & & $\begin{array}{c}0.653^{*} \\
(0.056)\end{array}$ \\
\hline Twitter usage (75th percentile) & & & & & & $\begin{array}{l}2.574^{\star \star \star} \\
(0.007)\end{array}$ & $\begin{array}{l}2.248^{\star \star \star} \\
(0.009)\end{array}$ \\
\hline Vector $X_{i}$ & $\checkmark$ & $\checkmark$ & $\checkmark$ & $\checkmark$ & $\checkmark$ & $\checkmark$ & $\checkmark$ \\
\hline Attack cluster FEs & $\checkmark$ & $\checkmark$ & $\checkmark$ & $\checkmark$ & $\checkmark$ & $\checkmark$ & $\checkmark$ \\
\hline$R^{2}$ & 0.751 & 0.769 & 0.787 & 0.752 & 0.754 & 0.759 & 0.806 \\
\hline Observations & 337 & 335 & 336 & 337 & 337 & 337 & 335 \\
\hline
\end{tabular}

Note: the dependent variable in all columns is Remain. Standard errors are clustered at the level of the closest terrorist-hit district (attack cluster). $p$-values are reported in parentheses. ${ }^{*} p<0.10 ;{ }^{* *} p<0.05 ;{ }^{* * *} p<0.01$

negative, statistically significant and stable in size across specifications. Some of these controls are plausibly post-treatment (such as UKIP support), and the inclusion of a large number of covariates can introduce multicollinearity problems (Colantone and Stanig 2018). However, the low sensitivity of our distance estimates in Columns 2-7 is quite reassuring as regards to biases arising from the potential omission of unobserved characteristics.

One potential explanation for the aforementioned results is that terrorism changes the composition of the electorate. If, for instance, proximity to terrorism increases the likelihood that public attitudes are translated into votes, then the positive Remain effects may be driven by higher post-treatment mobilization of the Remain supporters. To examine this possibility, we replace the dependent variable with districts' turnout rate (Turnout) ${ }^{12}$ and run the same regression set-up as in Table 1. The corresponding results, reported in Table 2, indicate that proximity to terrorism does not induce different turnout rates. As one would expect given its salience, being closer to terrorist-hit districts is associated with higher voter mobilization. Therefore the estimate on distance is negative, yet the effect is substantively small and fails to reach statistical significance in all specifications. Controlling for turnout rates in the regressions for 'Remain' has also little impact on the estimates reported in Table 1 (results available in Appendix Section A.3).

To corroborate our identification strategy, we re-estimate our model using IV techniques. Motivated by earlier studies, we instrument distance from recent attacks using 'historical' distance from attacks (for a recent application, see Wahl 2017); that is, the geodesic distance of a nonattacked district from the closest district that was hit by terrorism over the period 1970-1979 (the first 10 years for which data on terrorism are available in the GTD).

Since our historical distance measure refers to thirty attacks that occurred about four decades before the referendum, it is expected to influence the Remain vote indirectly through correlation with distance from future attacks. ${ }^{13}$ Table 3 shows the corresponding results. Column 1 reports the estimates for the baseline specification, whereas Column 2 shows robustness to introducing additional covariates. The first-stage coefficient on the instrument is positive and statistically significant at the 1 per cent level across all four columns. The F-test of excluded instruments also produces a very high F-statistic, documenting the strength of the instrument. The second-stage

\footnotetext{
${ }^{12}$ Appendix Figure A.4 provides a map with the turnout rates across districts (LADs).

${ }^{13}$ Twenty-two of the thirty 'historical' attacked districts were attacked only in the 1970s (and not in recent years). In Appendix Section B.2, we show that the probability of these twenty-two districts being attacked cannot be explained by any observable 'recent' characteristics, including population density and size.
} 
Table 2. Terrorism and turnout

\begin{tabular}{|c|c|c|c|c|c|c|c|}
\hline & 1 & 2 & 3 & 4 & 5 & 6 & 7 \\
\hline Distance & $\begin{array}{c}-0.004 \\
(0.317)\end{array}$ & $\begin{array}{c}-0.004 \\
(0.256)\end{array}$ & $\begin{array}{c}-0.003 \\
(0.454)\end{array}$ & $\begin{array}{c}-0.006 \\
(0.104)\end{array}$ & $\begin{array}{c}-0.004 \\
(0.320)\end{array}$ & $\begin{array}{c}-0.004 \\
(0.379)\end{array}$ & $\begin{array}{c}-0.004 \\
(0.280)\end{array}$ \\
\hline UKIP support & & $\begin{array}{c}-0.123 \\
(0.310)\end{array}$ & & & & & $\begin{array}{c}0.120 \\
(0.228)\end{array}$ \\
\hline Austerity shock & & & $\begin{array}{c}-2.022^{\star \star \star} \\
(0.000)\end{array}$ & & & & $\begin{array}{c}-1.812^{\star \star \star} \\
(0.000)\end{array}$ \\
\hline Pensioner share growth & & & & $\begin{array}{l}1.176^{\star \star \star} \\
(0.000)\end{array}$ & & & $\begin{array}{r}0.553^{\star} \\
(0.053)\end{array}$ \\
\hline Population & & & & & $\begin{array}{c}-0.385 \\
(0.117)\end{array}$ & & $\begin{array}{c}-0.326 \\
(0.107)\end{array}$ \\
\hline Twitter usage (75th percentile) & & & & & & $\begin{array}{c}-0.237 \\
(0.532)\end{array}$ & $\begin{array}{c}-0.061 \\
(0.851)\end{array}$ \\
\hline Vector $X_{i}$ & $\checkmark$ & $\checkmark$ & $\checkmark$ & $\checkmark$ & $\checkmark$ & $\checkmark$ & $\checkmark$ \\
\hline Attack cluster FEs & $\checkmark$ & $\checkmark$ & $\checkmark$ & $\checkmark$ & $\checkmark$ & $\checkmark$ & $\checkmark$ \\
\hline$R^{2}$ & 0.835 & 0.840 & 0.879 & 0.856 & 0.839 & 0.836 & 0.892 \\
\hline Observations & 337 & 335 & 336 & 337 & 337 & 337 & 335 \\
\hline
\end{tabular}

Note: the dependent variable in all columns is Turnout. Standard errors are clustered at the level of the closest terrorist-hit district (attack cluster). $p$-values are reported in parentheses. ${ }^{*} p<0.10 ;{ }^{* *} p<0.05 ;{ }^{* \star \star} p<0.01$

Table 3. Terrorism, the Remain vote and turnout: IV estimates

\begin{tabular}{|c|c|c|c|c|}
\hline & \multicolumn{2}{|c|}{ Remain } & \multicolumn{2}{|c|}{ Turnout } \\
\hline & 1 & 2 & 3 & 4 \\
\hline Distance & $\begin{array}{c}-0.031^{\star \star} \\
(0.012)\end{array}$ & $\begin{array}{c}-0.032^{\star \star \star} \\
(0.000)\end{array}$ & $\begin{array}{c}-0.011^{\star \star} \\
(0.021)\end{array}$ & $\begin{array}{c}-0.009^{\star \star \star} \\
(0.001)\end{array}$ \\
\hline UKIP support & & $\begin{array}{c}-1.485^{\star \star \star} \\
(0.000)\end{array}$ & & $\begin{array}{c}0.121 \\
(0.172)\end{array}$ \\
\hline Austerity shock & & $\begin{array}{c}-3.628^{\star * \star} \\
(0.000)\end{array}$ & & $\begin{array}{c}-1.814^{\star \star \star} \\
(0.000)\end{array}$ \\
\hline Pensioner share growth & & $\begin{array}{c}-0.636 \\
(0.259)\end{array}$ & & $\begin{array}{l}0.570^{\star \star} \\
(0.024)\end{array}$ \\
\hline Population & & $\begin{array}{c}0.659^{\star *} \\
(0.029)\end{array}$ & & $\begin{array}{r}-0.311^{\star} \\
(0.068)\end{array}$ \\
\hline Twitter usage (75th percentile) & & $\begin{array}{l}2.269^{\star * *} \\
(0.002)\end{array}$ & & $\begin{array}{r}-0.009 \\
(0.975)\end{array}$ \\
\hline First stage & & & & \\
\hline Distance (1970-1979) & $\begin{array}{l}0.925^{\star \star \star} \\
(0.000)\end{array}$ & $\begin{array}{l}0.913^{\star \star \star} \\
(0.000)\end{array}$ & $\begin{array}{l}0.925^{\star \star \star} \\
(0.000)\end{array}$ & $\begin{array}{l}0.913^{\star \star \star} \\
(0.000)\end{array}$ \\
\hline Vector $X_{i}$ & $\checkmark$ & $\checkmark$ & $\checkmark$ & $\checkmark$ \\
\hline Attack cluster FEs & $\checkmark$ & $\checkmark$ & $\checkmark$ & $\checkmark$ \\
\hline Excluded F-stat & 152.207 & 121.945 & 152.207 & 121.945 \\
\hline Observations & 337 & 335 & 337 & 335 \\
\hline
\end{tabular}

Note: standard errors are clustered at the level of the closest terrorist-hit district (attack cluster). $\mathrm{p}$-values are reported in parentheses. ${ }^{\star} p<0.10 ;{ }^{\star \star} p<0.05 ;{ }^{\star \star *} p<0.01$

results demonstrate that the magnitude of the coefficient on distance is relatively close to the ordinary least squares (OLS) one (reported in Table 1), which illustrates the absence of a strong endogeneity bias. Running the same IV regressions for 'Turnout' provides evidence that proximity to terrorism leads to statistically higher turnout rates, even though the effect is again substantively small (Columns 3-4).

\section{Robustness}

In the Appendix, we perform various tests to assess the robustness of our key findings. Specifically, we examine the sensitivity of our estimates to controlling for a broad set of additional district-level 
covariates (Section A.3), to reconstructing the attack distance measure based on a shorter time window or assigning a larger weight to attacks that occurred closer to the referendum date (Section A.4), to excluding regions (Section A.5) and to using alternative clustering of errors (Section A.6). Furthermore, we check whether our results hold when we introduce fixed effects at higher tiers of sub-national division (Section A.7) and when we employ categorical or non-linear measures of distance (Section A.8). In all cases, distance from terrorism has a negative and statistically significant effect on the Remain vote, providing further support for Hypothesis $1 \mathrm{~b}$. To rule out the possibility of a spurious relationship (or that our estimates are driven by unobserved factors associated with other types of distances), we also perform placebo tests in which we examine the effects on outcomes that are related to the referendum but should not be affected by distance from terrorism, such as people's perceptions of the economic consequences of Brexit. None of the placebo tests returns statistically significant estimates, which confirms the validity of our results (Section A.9).

Even though the official referendum results were published at the district (LAD) level, voting data at the level of electoral wards can also be obtained from Rosenbaum (2017). Unfortunately, this dataset covers only 13 per cent of the total number of wards in the UK and information on a wide range of socio-economic characteristics at such a disaggregated level is not available. Yet, this dataset allows us to test whether our results persist when we focus on variation within attacked districts, and to address concerns of ecological fallacy. To this end, we consider 367 wards located in nineteen terrorist-hit districts with data on the referendum results, and use differences in distances from attacked wards (within these districts) for identification. We also control for wards' degree of deprivation (composed of deprivation indices covering income, employment, education and skills, health and crime), as well as their population density and size, and add attacked-district fixed effects to capture unobserved characteristics that are shared by geographically close wards. The estimates obtained do not change the inferences drawn from the cross-district analysis: once again, we find that proximity to terrorism increases the Remain vote. Since all nineteen districts are classified as urban areas (most of them have major conurbation), these within-district results also provide further evidence that our terrorism effects do not reflect proximity-to-big-city effects. Appendix Section A.10 contains a full discussion of the ward-level analysis.

\section{Heterogeneous Effects}

The media are primarily responsible for providing information to the public in the aftermath of terrorist events, but they also can shape the salience of national rhetoric and reinforce the perception of threat (Hopkins 2010). The amount of reporting can thus be seen as a reflection of the event's relevance and national importance (Legewie 2013). Following these arguments, we expect our results to be much stronger for attacks that attracted prominent media attention. To test for this, we augment Equation 1 with an interaction term between distance and a measure of media reporting of the attack(s) that occurred in the closest terrorist-hit district. We focus on newspaper reporting for which data can be extracted from LexisNexis: an online service that searches through the text of thousands of news publications. We limit the search results to national newspapers from UK-based sources that include the term 'terrorism' or 'terrorist', the location, and other key words related to each attack, in the month following the attack. We then construct a proxy for high media coverage using attacks with ten or more LexisNexis hits (relevant articles), ${ }^{14}$ corresponding to nearly half of the attack clusters in our sample (twenty out of forty-three). Panel A of Figure 1 displays the marginal effects of 'Distance' at values 0 and 1 of 'High media coverage'. The evidence obtained confirms that media coverage plays an important role in moderating the effect of distance on the Remain vote: when the attacks are extensively covered by media, the corresponding estimate is four times as large.

\footnotetext{
${ }^{14} \mathrm{~A}$ binary indicator is less sensitive to outliers than a continuous measure and reduces the noise from not considering information from other media outlets.
} 
Panel A

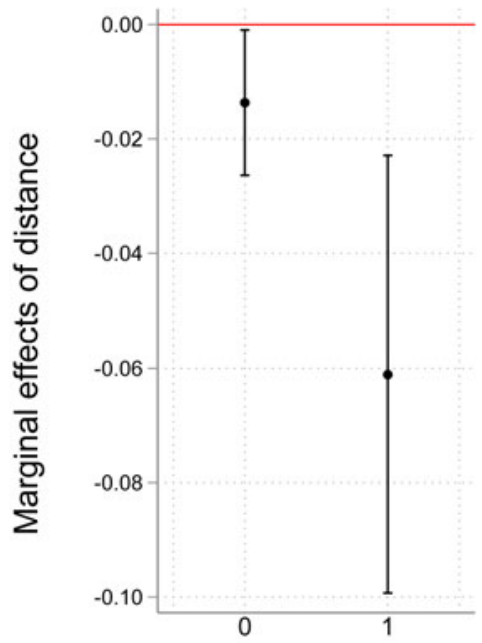

High media coverage
Panel B

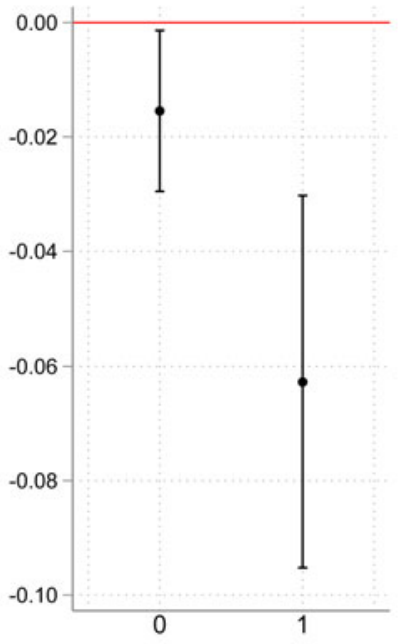

Muslim/jihadist perpetrators
Panel C

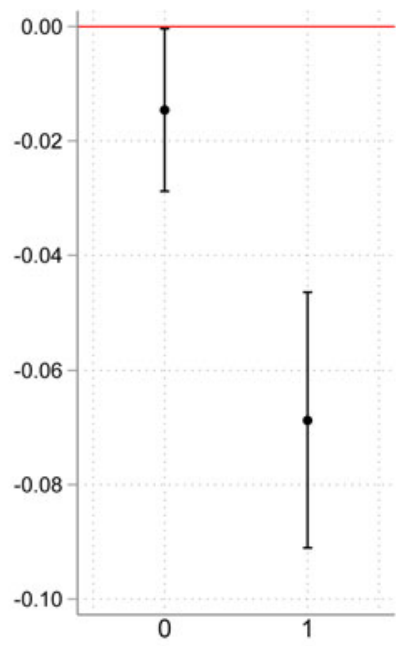

Fatal outcomes

Figure 1. Heterogeneous effects

Note: marginal effects of Distance at 0 and 1 values of the three conditioning binary variables. The dependent variable in all three panels is Remain. The estimates are calculated based on the specifications of Columns 1, 3 and 5 in Appendix Table A.9. All other covariates are held constant at their means. Solid vertical lines signify 95 per cent confidence intervals. Red horizontal line marks marginal effect of 0 .

Domestic terrorism is often portrayed as a minor threat committed by troubled, mentally ill loners, whereas terrorism motivated by a radical interpretation of Islam is framed as a hostile external force (Powell 2011). At the same time, when people are killed in an attack, the shock value and fear of terrorism are amplified (Zhang, Shoemaker and Wang 2013). To examine whether our results change when we focus on attacks with Muslim/jihadist perpetrators or those that involved deaths, we employ the same framework as in the previous paragraph and introduce interaction terms between distance and indicators capturing the occurrence of these types of attacks in the closest terrorist-hit district (five cases with Muslim/jihadist perpetrators and five cases with fatal outcomes). The corresponding marginal effects, reported in Panels B and $\mathrm{C}$ of Figure 1, confirm that proximity to terrorism has a more pronounced positive effect on the Remain vote when the perpetrators are members of an out-group or an external military movement, and when the attacks involve deaths.

Due to high correlation between the three conditioning factors, one has to be very cautious about prioritizing and uncovering links among them. Nevertheless, the analysis in this section clearly indicates that our findings are stronger for attacks that are deemed more relevant than others either due to their media attention-grabbing nature or their 'perceived' potential to be a national security threat. ${ }^{15}$

\section{Direct Exposure Effects}

An alternative way to answer our research question is to focus on the direct effect of terrorism on the Remain vote for the districts that were hit by terrorist attacks. Based on our results so far, this approach is likely to produce biased estimates due to the existence of spillover effects on the neighbouring districts. We do expect, however, that attacked districts will have a higher (on average) Remain vote share than the rest of the districts when the full sample of districts is taken into

\footnotetext{
${ }^{15}$ In Appendix Section A.11, we present the results of this section for both the Remain vote and the turnout rate, and explore their robustness to including the additional controls of Tables 1 and 2.
} 
account. In Appendix Section B.1, we perform an analysis along these lines and use matching techniques to address the endogeneity problem of the terrorism location choice. Specifically, we estimate the effect of terrorism as the difference in the sample average of the Remain vote between treated observations and a group of matched control observations, which are carefully selected based on coarsened exact matching (Iacus, King and Porro 2012). To do that, we first identify the most prevalent district-level characteristics influencing the probability of experiencing a terrorist attack. We find that districts with high levels of crime and a history of attacks (which also tend to be more populated areas) are more likely to be hit by terrorism. We then match attacked districts with nonattacked districts based on these characteristics. The results confirm that districts that experienced an attack are indeed associated with a stronger Remain vote relative to those that are similar in terms of terrorism determinants but did not experience an attack. If anything, this approach increases our confidence in our main finding: terrorism is associated with increased support for Remain.

\section{Individual-Level Analysis}

\section{Data and Methodology}

To shed light on the micro-foundations underlying the terrorism-induced Remain effects at the regional level, we use individual-level data from the BES. Exploiting information from the survey waves that coincide with terrorist attacks allows us to examine the causal effect of terrorism on people's responses. Our identification strategy relies on the assumption that the timing of attacks is exogenous to that of the interviews, and thus individuals interviewed after the attack can be defined as the 'treatment' group whereas those interviewed before serve as the 'control' group (Balcells and Torrats-Espinosa 2018; Muñoz, Falcó-Gimeno and Hernández 2020).

We consider three of the five major terrorist attacks that occurred in 2016 and $2017::^{16}$ the murder of MP Jo Cox (16 June 2016), the Manchester Arena bombing (22 May 2017) and the Finsbury Park attack (19 June 2017). We choose these attacks for two reasons. First, they received widespread media coverage and resulted in deaths, which makes them particularly impactful and relevant. Secondly, they overlapped with recent BES waves $(8,12$ and 13 , respectively) containing comparable information on attitudes about and perceptions of the EU. ${ }^{17}$

In particular, we infer individuals' pro-EU sentiment from their answer to the following question, which is worded in exactly the same way across the three waves: 'Some people feel that Britain should do all it can to unite fully with the EU. Other people feel that Britain should do all it can to protect its independence from the EU. Where would you place yourself on a $0-10$ scale?' (higher values indicate more positive attitudes about the EU). We then estimate the causal effect of terrorist attacks on EU attitudes using the following model (see also Balcells and Torrats-Espinosa 2018):

$$
{ }^{\prime} \text { Pro-EU' }{ }_{n k w}=\gamma^{\prime} \text { Post-attack' }{ }_{n k w}+\delta Z_{n k w}+\lambda_{k w}+u_{n k w}
$$

where 'Pro-EU' ${ }_{n k w}$ captures the response to the above question for individual $n$, living in region $k$, interviewed in survey wave $w$; 'Post-attack' ${ }_{n k w}$ is a binary indicator that takes a value of 1 if the individual was interviewed after the day of the attack, and 0 otherwise; ${ }^{18} Z_{n k w}$ is a vector that

\footnotetext{
${ }^{16}$ The two other major attacks are the Westminster Bridge attack (22 March 2017) and the London Bridge attack (3 June 2017). We do not consider the former since its timing did not coincide with the timing of BES waves. We do not consider the latter since it occurred towards the end of Wave 12. Moreover, the Manchester Arena bombing (Wave 12) took place 11 days earlier, and thus the individuals interviewed between the two attacks are already defined as 'treated'.

${ }^{17}$ In Appendix Section C.2, we provide additional information on these attacks. To show that the individuals in our sample were aware of these attacks, we also provide examples of national newspaper front pages covering the attacks the day after they occurred.

${ }^{18}$ In all three cases, the attack appeared in national newspapers the following day. Dropping individuals who were interviewed on the day of the attacks does not change our results.
} 
includes the following individual-level control variables: gender, age, age squared, level of education (low, medium, high) and the political party for which the interviewee voted in the 2015 general election; $\lambda_{k w}$ represents region-by-wave fixed effects; and $u_{n k w}$ is an error term. ${ }^{19}$ Our parameter of interest, $\gamma$, measures the effect of terrorism on EU attitudes; a positive value indicates that exposure to terrorism sways the population towards a more pro-EU sentiment.

A possible threat to our identification strategy is that individuals with specific characteristics may respond to the survey at different points in time, and these characteristics may be predictive of the outcome. In Appendix Section C.3, we show that there is a strong balance in observed characteristics (included in vector $Z_{n k w}$ ) across treatment and control units.

To further ensure that our results are not affected by such differences, we report estimates both before and after augmenting the specification with vector $Z_{n k w}{ }^{20}$ Note that the inclusion of region-by-wave fixed effects restricts the pre- and post-attack comparisons to individuals interviewed in the same wave and living in the same region, which can also remove any biases arising from systematic differences in how the different waves were fielded (Balcells and Torrats-Espinosa 2018). To check the sensitivity of our estimates to the regions considered, we start with the least restrictive specification, where regions are captured by GORs, and re-estimate the model using counties $^{21}$ and districts as our regional units.

\section{Results}

Table 4 presents the OLS estimation results of Equation 2. Column 1 refers to a simple specification that regresses our treatment variable on the outcome variable, whereas Columns 2 and 3 progressively add GOR-by-wave fixed effects and the variables in vector $Z_{n k w}$. The estimates obtained show that citizens take a more positive stance towards the EU after terrorist attacks: the coefficient on Post-attack is positive and highly statistically significant across all three specifications. In Columns 4-7, we run the same regression set-up as in Columns 2-3, but we now control for fixed effects at finer administrative levels: counties and districts. The results have similar magnitudes and levels of statistical significance. In particular, the estimated coefficient of the treatment variable in Columns 2-7 suggests that exposure to a new terrorist attack strengthens the pro-EU sentiment by about 0.1 units ( 1 percentage point on the $0-10$ scale) ${ }^{22}$

As discussed in the previous sections, geographic proximity to a terrorist attack is expected to amplify the perception of threat and the personal sense of vulnerability, leading to stronger postattack reactions. Columns 8-10 of Table 4 provide evidence in line with this argument. When we restrict the sample to include individuals living in the counties of the three terrorist attacks, the treatment effect becomes nearly four times as large, even though it is now less precisely estimated due to the smaller sample. ${ }^{23}$ This finding also adds further support to the use of distance from terrorism as our key explanatory variable.

\section{Robustness}

In the Appendix, we present additional analyses and robustness checks. In Section C.4, we re-estimate Equation 2 separately for each attack/wave. In all cases, we find that individuals place themselves closer to the idea of Britain uniting fully with the EU after they are exposed to an attack. However, the results are stronger and statistically more robust for the Manchester

\footnotetext{
${ }^{19}$ Appendix Section C.1 provides an overview of the variables used in the analysis.

${ }^{20}$ In Appendix Section C.3, we also show that our results hold when we rely on coarsened exact matching to pre-process the data and produce covariate balance between the treatment and control groups.

${ }^{21}$ England, Scotland and Wales are divided into forty counties (NUTS2 regions).

${ }^{22}$ The results are robust to using ordered probit (OP) estimation rather than OLS.

${ }^{23}$ The stronger treatment effect for attacked counties compared to non-attacked counties is broadly confirmed when we carry out a test of the hypothesis that estimates on Post-attack for the two samples are statistically the same (see Table 4).
} 
Table 4. Terrorism and pro-EU sentiment: individual-level analysis

\begin{tabular}{|c|c|c|c|c|c|c|c|c|c|c|}
\hline & \multicolumn{7}{|c|}{ All respondents } & \multicolumn{3}{|c|}{ Within attacked counties } \\
\hline & 1 & 2 & 3 & 4 & 5 & 6 & 7 & 8 & 9 & 10 \\
\hline Post-attack & $\begin{array}{l}0.202^{\star * *} \\
(0.000)\end{array}$ & $\begin{array}{l}0.130^{\star * *} \\
(0.000)\end{array}$ & $\begin{array}{l}0.093^{\star \star *} \\
(0.006)\end{array}$ & $\begin{array}{l}0.136^{* * *} \\
(0.000)\end{array}$ & $\begin{array}{l}0.093^{\star * *} \\
(0.006)\end{array}$ & $\begin{array}{l}0.126^{\star \star \star} \\
(0.001)\end{array}$ & $\begin{array}{c}0.083^{\star *} \\
(0.015)\end{array}$ & $\begin{array}{l}0.453^{\star *} \\
(0.033)\end{array}$ & $\begin{array}{c}0.373^{\star} \\
(0.082)\end{array}$ & $\begin{array}{r}0.313^{*} \\
(0.074)\end{array}$ \\
\hline GOR-by-wave FEs & & $\checkmark$ & $\checkmark$ & & & & & & & \\
\hline County-by-wave FEs & & & & $\checkmark$ & $\checkmark$ & & & & & \\
\hline District-by-wave FEs & & & & & & $\checkmark$ & $\checkmark$ & & $\checkmark$ & $\checkmark$ \\
\hline Vector $Z_{n k w}$ & & & $\checkmark$ & & $\checkmark$ & & $\checkmark$ & & & $\checkmark$ \\
\hline$R^{2}$ & 0.001 & 0.035 & 0.320 & 0.044 & 0.322 & 0.073 & 0.336 & 0.003 & 0.059 & 0.331 \\
\hline Observations & 72,828 & 72,828 & 62,529 & 72,828 & 62,529 & 72,828 & 62,529 & 1,920 & 1,920 & 1,650 \\
\hline Diff-test & & & & & & & & 0.054 & 0.109 & 0.080 \\
\hline
\end{tabular}

Note: standard errors are clustered at the district level. p-values are reported in parentheses. Diff-test reports the p-value of a one-sided test, where H0: the difference in the Post-attack estimates between the sample of attacked counties and the sample of non-attacked counties is equal to zero, and H1: the difference in the estimates between the two samples is positive. ${ }^{\star} p<0.10$; ${ }^{\star \star} p<0.05$; ${ }^{* \star \star} p<0.01$ 
Table 5. Perceptions of terrorism outside the EU: individual-level analysis

\begin{tabular}{|c|c|c|c|c|c|c|c|c|c|c|}
\hline & \multicolumn{7}{|c|}{ All respondents } & \multicolumn{3}{|c|}{ Within attacked counties } \\
\hline & 1 & 2 & 3 & 4 & 5 & 6 & 7 & 8 & 9 & 10 \\
\hline Post-attack & $\begin{array}{l}0.015^{\star \star \star} \\
(0.008)\end{array}$ & $\begin{array}{l}0.015^{\star \star \star} \\
(0.008)\end{array}$ & $\begin{array}{l}0.015^{\star \star} \\
(0.013)\end{array}$ & $\begin{array}{l}0.015^{\star \star \star} \\
(0.008)\end{array}$ & $\begin{array}{l}0.015^{\star \star} \\
(0.013)\end{array}$ & $\begin{array}{l}0.015^{\star *} \\
(0.013)\end{array}$ & $\begin{array}{l}0.015^{\star \star} \\
(0.017)\end{array}$ & $\begin{array}{c}0.059^{\star \star} \\
(0.043)\end{array}$ & $\begin{array}{c}0.061^{\star \star} \\
(0.031)\end{array}$ & $\begin{array}{r}0.037 \\
(0.251)\end{array}$ \\
\hline GOR-by-wave FEs & & $\checkmark$ & $\checkmark$ & & & & & & & \\
\hline County-by-wave FEs & & & & $\checkmark$ & $\checkmark$ & & & & & \\
\hline LAD-by-wave FEs & & & & & & $\checkmark$ & $\checkmark$ & & $\checkmark$ & $\checkmark$ \\
\hline Vector $Z_{n k w}$ & & & $\checkmark$ & & $\checkmark$ & & $\checkmark$ & & & $\checkmark$ \\
\hline$R^{2}$ & 0.000 & 0.004 & 0.051 & 0.006 & 0.052 & 0.020 & 0.066 & 0.002 & 0.027 & 0.100 \\
\hline Observations & 52,338 & 52,338 & 44,537 & 52,338 & 44,537 & 52,338 & 44,537 & 1,278 & 1,278 & 1,083 \\
\hline Diff-test & & & & & & & & 0.040 & 0.026 & 0.226 \\
\hline
\end{tabular}

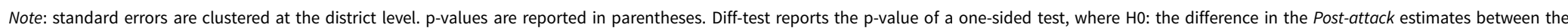
sample of attacked counties and the sample of non-attacked counties is equal to zero, and H1: the difference in the estimates between the two samples is positive. ${ }^{\star} p<0.10$; ${ }^{\star \star} \mathrm{p}<0.05 ;{ }^{\star \star \star} \mathrm{p}<0.01$ 
Arena bombing, which was a very shocking and sensational event with a large number of casualties. In Sections C.5, C.6 and C.7, we check the sensitivity of our results to using alternative clustering of errors, to accounting for the baseline level of our outcome variable based on a difference-in-differences design, and to using a short (3-day) time window. In all cases, our results do not change the inferences from the earlier findings.

In Section C.8, we perform two placebo tests - one based on an unrelated outcome variable and one based on unrelated time trends. As expected, both tests return (economically and statistically) insignificant coefficients. In Section C.9, we explore the treatment effect on citizens' beliefs about the most important issue facing the country. The analysis reveals that after an attack, individuals are far more likely to perceive terrorism as the top national problem as opposed to other popular issues, such as the economy and immigration. Finally, in Section C.10, we aggregate the individual-level data to the district level and interact the treatment variable with the distance from terrorist attacks. The corresponding estimates confirm that post-attack reactions are a positive function of geographic proximity to terrorism. Taken together, the alternative estimation strategies and robustness checks presented in Appendix C lend strong credibility to our causal claims.

\section{Risk of Terrorism Outside the EU}

Our results so far demonstrate that exposure to a new terrorist attack increases positive attitudes towards the EU. One of the arguments put forward in this article is that, in the aftermath of terrorist attacks, citizens reconsider the risks involved in leaving the EU, particularly in the security domain. To test this argument more directly, we run a final round of analyses and replace the dependent variable with citizens' responses to the following BES question: 'Do you think the risk of terrorism would be higher, lower or about the same if the UK leaves the European Union?' The limitation of this question is that it cannot be used for the Manchester Arena bombing (Wave 12), as it was included in Waves 8 and 13 only. We code the responses 'higher' and 'much higher' as 1 - and all the other responses 0 - and estimate a linear probability model using the same regression set-up as in Table 4. We find that, after a terrorist attack, individuals are 1.5 percentage points more likely to report that the risk of terrorism will be higher if the country leaves the EU, and, once again, the results become stronger when we focus on individuals living in the counties of the two terrorist attacks (see Table 5). All in all, our findings confirm that citizens believe that a more effective response to terrorism is at the EU rather than the national level.

\section{Conclusions}

The UK has long struggled against terrorism and political violence within its borders, which has made counter-terrorism efforts a key priority for policy makers and a main concern for the public. By combining evidence from district- and ward-level data with a wealth of evidence stemming from individual, survey-based data, this article provides a comprehensive study of the effect of terrorism on voting in the Brexit referendum. Our results suggest that higher exposure to terrorism (as captured by proximity to terrorist attacks) is associated with increased support for Remain. Our results also suggest that this effect is likely driven by an increase in voters' perception of the benefits of EU membership and the risks to security and safety posed by the UK's departure from the EU. To assess and substantiate causal inference, we employ alternative estimation strategies and conduct numerous robustness and sensitivity checks, and our results hold.

Our analysis informs the ongoing policy debates on the factors that affected the Brexit vote, on public opinion in favour of European unification, and on the short- and long-term behavioural and attitudinal consequences of terrorism. While terrorism raises the salience of security issues and affects overall individual attitudes towards the EU (as documented in this article), security considerations were perhaps not given sufficient space in the debate leading up to the referendum. As Brexit could potentially affect the UK's cooperation with law enforcement and 
intelligence partners by, for instance, limiting its access to data and process systems - such as the European Arrest Warrants and the European Criminal Records Information System - potential risks to counter-terrorism efforts should be taken into account in post-Brexit security policies.

Supplementary material. Online appendices are available at https://doi.org/10.1017/S0007123420000927.

Data availability statement. Data replication sets are available in Harvard Dataverse at: https://doi.org/10.7910/DVN/ SHL8DM

Acknowledgements. We thank Özlem Atikcan, Sarah Brown, Tatiana Coutto, Jessica Di Salvatore, Charlotte Heath-Kelly, Steven McIntosh, Andreas Murr, Enzo Nussio, Sergi Pardos-Prado, four anonymous referees and the editor, Rob Johns, for helpful comments and suggestions. We are also indebted to the participants of the 44th Symposium of the Spanish Economic Association, and research seminars at the University of Sheffield, the University of Warwick and the University of York. The usual disclaimer applies.

\section{References}

Atikcan EÖ (2015) The puzzle of double referendums in the European Union. JCMS: Journal of Common Market Studies 53(5), 937-956.

Atikcan EÖ, Nadeau R and Bélanger É (2020) Framing Risky Choices: Brexit and the Dynamics of High-Stakes Referendums. Montreal: McGill-Queen's University Press.

Balcells L and Torrats-Espinosa G (2018) Using a natural experiment to estimate the electoral consequences of terrorist attacks. Proceedings of the National Academy of Sciences 115(42), 10624-10629.

Becker S, Fetzer T and Novy D (2017) Who voted for Brexit? A comprehensive district-level analysis. Economic Policy 32(92), 601-650.

Berrebi C and Klor EF (2008) Are voters sensitive to terrorism? Direct evidence from the Israeli electorate. American Political Science Review 102(3), 279-301.

Birkelund GE et al. (2019) Do terrorist attacks affect ethnic discrimination in the labour market? Evidence from two randomized field experiments. The British Journal of Sociology 70(1), 241-260.

Böhmelt T, Bove V and Nussio E (2019) Can terrorism abroad influence migration attitudes at home? American Journal of Political Science 64(3), 437-451.

Bove V and Böhmelt T (2016) Does immigration induce terrorism? The Journal of Politics 78(2), 572-588.

Bove V, Efthyvoulou G, Pickard H (2020) Replication data for 'Did terrorism affect voting in the Brexit referendum?' https:// doi.org/10.7910/DVN/SHL8DM, Harvard Dataverse, V1, UNF:6:8nUopO5wscpLqtlHS707Ew== [fileUNF]

Bove V, Böhmelt T and Nussio E (2021) Terrorism abroad and migration policies at home. Journal of European Public Policy 28(2), 190-207.

Braithwaite A (2013) The logic of public fear in terrorism and counter-terrorism. Journal of Police and Criminal Psychology 28(2), 95-101.

Bratti M et al. (2017) What are you voting for? Proximity to refugee reception centres and voting in the 2016 Italian constitutional referendum. Technical report, IZA DP. 11060.

Browning CS (2018) 'Je suis en terrasse': political violence, civilizational politics, and the everyday courage to be. Political Psychology 39(2), 243-261.

Chan TW et al. (2017) Understanding the social and cultural bases of Brexit. Technical report, Department of Quantitative Social Science-UCL Institute of Education, University College London, DOQSS Work (17-15), pp. 1-39.

Clarke HD, Goodwin M and Whiteley P (2017a) Why Britain voted for Brexit: an individual-level analysis of the 2016 referendum vote. Parliamentary Affairs 70(3), 439-464.

Clarke HD, Goodwin M and Whiteley PF (2017b) Brexit: Why Britain Voted to Leave the European Union. Cambridge: Cambridge University Press.

Colantone I and Stanig P (2018) Global competition and Brexit. American Political Science Review 112(2), 201-218.

Davis L and Deole SS (2017) Immigration and the rise of far-right parties in Europe. IFO DICE Report 15(4), 10-15.

Dinesen PT and Jæger MM (2013) The effect of terror on institutional trust: new evidence from the 3/11 Madrid terrorist attack. Political Psychology 34(6), 917-926.

Enders W, Sandler T and Gaibulloev K (2011) Domestic versus transnational terrorism: data, decomposition, and dynamics. Journal of Peace Research 48(3), 319-337.

Fetzer T (2019) Did austerity cause Brexit? American Economic Review 109(11), 3849-3886.

Fischhoff B et al. (2003) Judged terror risk and proximity to the World Trade Center. Journal of Risk and Uncertainty 26(2), $137-151$.

Garry J (2014) Emotions and voting in EU referendums. European Union Politics 15(2), 235-254.

Getmansky A and Zeitzoff T (2014) Terrorism and voting: the effect of rocket threat on voting in Israeli elections. American Political Science Review 108(3), 588-604. 
Goodwin M, Hix S and Pickup M (2020) For and against Brexit: a survey experiment of the impact of campaign effects on public attitudes toward EU membership. British Journal of Political Science 50(2), 481-495.

Goodwin M and Milazzo C (2017) Taking back control? Investigating the role of immigration in the 2016 vote for Brexit. The British Journal of Politics and International Relations 19(3), 450-464.

Goodwin MJ and Heath O (2016) The 2016 referendum, Brexit and the left behind: an aggregate-level analysis of the result. The Political Quarterly 87(3), 323-332.

Hopkins DJ (2010) Politicized places: explaining where and when immigrants provoke local opposition. American Political Science Review 104(1), 40-60.

Huddy L and Feldman S (2011) Americans Respond politically to 9/11: understanding the impact of the terrorist attacks and their aftermath. American Psychologist 66(6), 455-467.

Huddy L et al. (2005) Threat, anxiety, and support of antiterrorism policies. American Journal of Political Science 49(3), 593-608.

Iacus S, King G and Porro G (2012) Causal inference without balance checking: coarsened exact matching. Political Analysis 20(1), 1-24.

Larsen EG, Cutts D and Goodwin MJ (2019) Do terrorist attacks feed populist Eurosceptics? Evidence from two comparative quasi-experiments. European Journal of Political Research 59(1), 182-205.

Legewie J (2013) Terrorist events and attitudes toward immigrants: a natural experiment. American Journal of Sociology 118(5), 1199-1245.

Liñeira R and Henderson A (2019) Risk attitudes and independence vote choice. Political Behavior. https://doi.org/10.1007/ s11109-019-09560-x.

Marcus GE, Neuman WR and MacKuen M (2000) Affective Intelligence and Political Judgment. Chicago, IL: University of Chicago Press.

Marineau J et al. (2020) The local geography of transnational terrorism. Conflict Management and Peace Science 37(3), 350-381.

McLaren LM (2002) Public support for the European Union: cost/benefit analysis or perceived cultural threat? The Journal of Politics 64(2), 551-566.

Muñoz J, Falcó-Gimeno A and Hernández E (2020) Unexpected event during survey design: promise and pitfalls for causal inference. Political Analysis 28(2), 186-206.

Neumayer E, Plümper T and Epifanio M (2014) The 'peer-effect' in counterterrorist policies. International Organization 68(1), 211-234.

Nussio E, Bove V and Steele B (2019) The consequences of terrorism on migration attitudes across Europe. Political Geography 75, 102047.

Pickard HG (2019) A mailshot in the dark? The impact of the UK government's leaflet on the 2016 EU referendum. Sheffield Economic Research Paper Series No. 2019004.

Powell KA (2011) Framing Islam: an analysis of US media coverage of terrorism since 9/11. Communication Studies 62(1), 90-112.

Rosenbaum M (2017). Voting data sheds light on referendum. BBC News. Available from https://www.bbc.co.uk/news/ukpolitics-38762034 (accessed 25 February 2019).

Vázquez C, Pérez-Sales P and Hervás G (2008) Positive effects of terrorism and posttraumatic growth: an individual and community perspective. In Linley A and Joseph S (eds), Trauma, Recovery, and Growth: Positive Psychological Perspectives on Posttraumatic Stress. Hoboken, NJ: Wiley, pp. 63-91.

Wahl F (2017) Does European development have Roman roots? Evidence from the German Limes. Journal of Economic Growth 22(3), 313-349.

Zagefka H (2018) It could have been me: proximity motivates disaster giving. International Journal of Nonprofit and Voluntary Sector Marketing 23(1).

Zhang D, Shoemaker PJ and Wang X (2013) Reality and newsworthiness: press coverage of international terrorism by China and the United States. Asian Journal of Communication 23(5), 449-471.

Cite this article: Bove V, Efthyvoulou G, Pickard H (2022). Did Terrorism Affect Voting in the Brexit Referendum? British Journal of Political Science 52, 1133-1150. https://doi.org/10.1017/S0007123420000927 